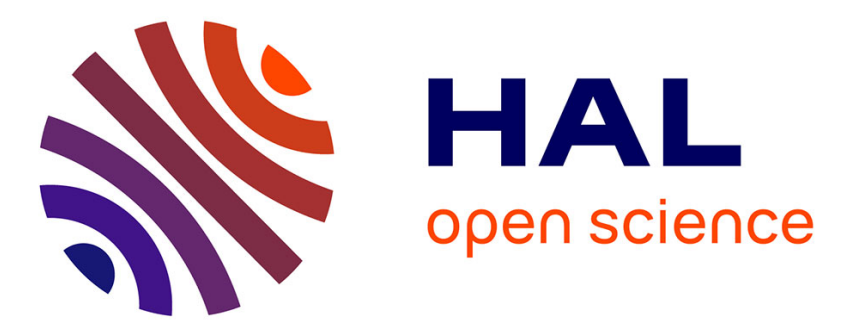

\title{
Thermo-Physical and Physical Properties for Use in Solidification Modelling of Multi-Component Alloys
}

\author{
N. Saunders, Z. Guo, A. P Miodownik, J-Ph. Schillé
}

\section{To cite this version:}

N. Saunders, Z. Guo, A. P Miodownik, J-Ph. Schillé. Thermo-Physical and Physical Properties for Use in Solidification Modelling of Multi-Component Alloys. Solidification and Crystallization, 2004, 9783527603503. 10.1002/3527603506.ch10 . hal-03349329

\section{HAL Id: hal-03349329 \\ https://hal.science/hal-03349329}

Submitted on 20 Sep 2021

HAL is a multi-disciplinary open access archive for the deposit and dissemination of scientific research documents, whether they are published or not. The documents may come from teaching and research institutions in France or abroad, or from public or private research centers.
L'archive ouverte pluridisciplinaire HAL, est destinée au dépôt et à la diffusion de documents scientifiques de niveau recherche, publiés ou non, émanant des établissements d'enseignement et de recherche français ou étrangers, des laboratoires publics ou privés.

\section{(ㅇ)(1) $\$$}

Distributed under a Creative Commons Attribution - NonCommercial - NoDerivatives $\mid 4.0$ 
This is the peer reviewed version of the following article:

Thermo-Physical and Physical Properties for Use in Solidification Modelling of Multi-Component Alloys, N. Saunders,Z. Guo, A. P. Miodownik, J-Ph. Schillé, in "Solidification and Crystallization", ed. D.M. Herlach, Wiley-VCH Verlag GmbH \& Co. KGaA, 2004

which has been published in final form at

\section{https://doi.org/10.1002/3527603506.ch10.}

This article may be used for non-commercial purposes in accordance with Wiley Terms and Conditions for Use of Self-Archived Versions. This article may not be enhanced, enriched or otherwise transformed into a derivative work, without express permission from Wiley or by statutory rights under applicable legislation. Copyright notices must not be removed, obscured or modified. The article must be linked to Wiley's version of record on Wiley Online Library and any embedding, framing or otherwise making available the article or pages thereof by third parties from platforms, services and websites other than Wiley Online Library must be prohibited. 


\title{
THERMO-PHYSICAL AND PHYSICAL PROPERTIES FOR USE IN SOLIDIFICATION MODELLING OF MULTI-COMPONENT ALLOYS
}

\author{
N. Saunders ${ }^{\S}$, Z. Guo ${ }^{\circ}$ A. P. Miodownik ${ }^{\S}$ and J-Ph. Schilléo \\ $\S$ Thermotech Ltd., Surrey Technology Centre \\ The Surrey Research Park, Guildford GU2 7YG, U.K. \\ ${ }^{\circ}$ Sente Software Ltd., Surrey Technology Centre \\ The Surrey Research Park, Guildford GU2 7YG, U.K.
}

\begin{abstract}
The thermo-physical and physical properties of the liquid and solid phases are critical components in casting simulations. Such properties include the fraction solid transformed, enthalpy release, thermal conductivity, volume and density, all as a function of temperature. Due to the difficulty in experimentally determining such properties at solidification temperatures, little information exists for multi-component alloys. As part of the development of a new computer programme for modelling of materials properties, JMatPro, extensive work has been carried out on the development of sound, physically based models for these properties. Wide-ranging results have previously been presented for $\mathrm{Fe}, \mathrm{Ni}, \mathrm{Ti}, \mathrm{Al}$ and $\mathrm{Mg}$-based alloys. The purpose of the present paper is to look at how changes in composition can substantially affect properties of multi-component alloys during solidification and further demonstrate how properties of the liquid can substantially vary in the mushy zone.
\end{abstract}

\section{INTRODUCTION}

In solidification modelling, there is often a requirement for high quality information concerning thermo-physical and physical properties. Some properties have been measured for specific alloys, but the number of alloys where information is available is limited. Furthermore, the information may be incomplete, in that not all properties measured and, sometimes, disparate information from a variety of sources is used to build up the data for a specific alloy. The latter method can inherit inconsistency as the composition of the alloys used to build up the property database may not be the same and various important temperatures (i.e. solidus, invariant reactions) may differ between the alloys. Furthermore, there may be variations linked to different experimental conditions.

An advantage of using a calculation route to provide properties is that the calculation is internally self-consistent. It can therefore provide extensive information on how the properties of an alloy may change within a specification range as well as providing detailed information on the properties of the liquid phase in the mushy zone. Furthermore, it will be made clear from the examples presented in this paper that properties experimentally measured in the fully liquid state cannot be extrapolated into the mushy zone with any confidence. Such detail is important in modelling defect formation and is something that is usually beyond the capability of measurement.

The self-consistent calculation of thermo-physical and physical properties is further potentially important in determining unknown properties, such as the heat transfer coefficient at the ingot/mold 
interface, through inverse modelling. In this case, a full set of consistently calculated properties may lead to a more rigorous estimate and understanding of this property.

It is also noted that, sometimes, experimentally determined properties that are not appropriate to solidification are used. For example, solidus values that are more appropriate to the melting of heat-treated, homogenised alloys [1] rather than the solidus resulting from solidification [2] have been used for solidification modelling of the Ni-based superalloy $718[3,4]$. In this circumstance, the freezing temperature range is likely to be underestimated by more than a factor of 2 . Similarly, thermal conductivities are available for 718 [5], but these will also be appropriate for homogenised alloys, rather than for solidification.

Previous modelling work $[6,7,8,9,10,11,12,13]$ has shown that excellent results can be obtained for the phases formed during solidification, as well as their composition and temperature range of formation, by using thermodynamic modelling based on the CALPHAD [14] methodology. Such modelling can be further extended to calculate thermo-physical and physical properties over the complete relevant temperature range for a wide range of alloys $[15,16,17,18,19]$. The present paper briefly describes the methodology. A significant advantage of the current method is that properties for each phase are calculated so fine detail can be obtained: for example, the density change of the liquid during the solidification, which is governed both by an intrinsic change with temperature and by the composition changes that accompany solidification.

The current work forms part of the development of a more generalised software package (JMatPro) for the calculation of a wide range of materials properties. [19,20] A feature of the new programme is that great store has been placed on using models that, as far as possible, are based on sound physical principles rather than purely statistical methods. Thus, many of the shortcomings of methods such as regression analysis can be overcome. For example, the same models and input parameters are used for density calculations for all alloy types, whether it be for a commercially pure Al-alloy or a complex Ni-based superalloy.

\section{TECHNICAL BACKGROUND}

\subsection{The Scheil-Gulliver approach with modification for fast $C$ and $N$ diffusion}

The SG model can be considered as a complementary limiting case to equilibrium solidification whereby it is assumed that solute diffusion in the solid phase is small enough to be considered negligible and that diffusion in the liquid is extremely fast, fast enough to assume that diffusion is complete. Based on the premise that liquidus and solidus lines are linear, the composition of solid formed during solidification $\left(C_{o}\right)$, as a function of the fraction of solid formed $\left(f_{s}\right)$ can be expressed as

$$
C_{s}=k C_{o}\left(1-f_{s}\right)^{k-1}
$$

where $C_{o}$ is the composition of the alloy and $k$ is the partition coefficient. From this the fraction solid formed as a function of temperature is given by [21]

$$
f_{s}=1-\left(\frac{T_{f}-T}{T_{f}-T_{L}}\right)^{\left[\frac{1}{k-1}\right]}
$$

where $T_{L}$ and $T_{f}$ are the liquidus and solidus temperature. The treatment above is the traditional derivation of the Scheil equation but it has quite severe restrictions when applied to multi- 
component alloys. It is not possible to derive this equation, using the same mathematical method, if the partition coefficient, $\mathrm{k}$, is dependent on temperature and/or composition. The Scheil equation is applicable only to dendritic solidification and cannot, therefore, be applied to eutectic alloys that are common type for $\mathrm{Al}$ and Mg-alloys. Further it cannot be used to predict the formation of intermetallics during solidification.

Using thermodynamic modelling all of the above disadvantages can be overcome. The process that physically occurs during 'Scheil' solidification can be envisaged as follows. A liquid of composition $\mathrm{C}_{\mathrm{o}}$ is cooled to a small amount below its liquidus. It precipitates out solid with a composition $\mathrm{C}_{\mathrm{S}, 1}$ and the liquid changes its composition to $\mathrm{C}_{\mathrm{L}, 1}$. However, on further cooling the initial solid cannot change its composition due to lack of back diffusion and it is effectively 'isolated'. A local equilibrium is then set up where the liquid of composition $\mathrm{C}_{\mathrm{L}, 1}$ transforms to a liquid of composition $\mathrm{C}_{\mathrm{L}, 2}$ and a solid with composition $\mathrm{C}_{\mathrm{S}, 2}$, which is precipitated onto the original solid with composition $\mathrm{C}_{\mathrm{S}, 1}$. This process occurs continuously during cooling and, when $\mathrm{k}<1$, leads to the solid phase becoming lean in solute in the center of the dendrite and the liquid becoming more and more enriched in solute as solidification proceeds. Eventually, the composition of the liquid will reach the eutectic composition and final solidification will occur via this reaction.

Any appearance of secondary phases can be easily taken into account in this approach with the assumption that no back diffusion occurs in them. Therefore, all transformations can be accounted for, including the final eutectic solidification. The approach described here is based on an isothermal step process but as the temperature step size becomes small it provides results that are almost completely equivalent to that which would be obtained from continuous cooling. A further and very significant advantage of using a thermodynamic approach is that the heat evolution during solidification is a straightforward product of the calculation.

The limit to the SG simulation is that some back diffusion will take place. However, if its degree is small, good results will still be obtained. For example, Backerud et al. [22] have experimentally studied almost 40 commercial alloys and calculated results have been compared to all of these. Results of the comparisons of fraction solid vs. temperature for some of these alloys are shown in Figure 1. The agreement is most striking and the level of accuracy achieved for these alloys is quite typical of that attained overall in the comparison. A further example is in Ni-based superalloys where differential thermal analysis (DTA) and microstructural studies were done for a 706 alloy and directly compared with calculations [11]. Figure 2 shows the calculated fractions solid vs. temperature plot, while Table I shows the agreement between calculated and experimentally determined critical temperatures. An advantage of the calculation method was the correct prediction that the $\eta$ phase would form during solidification. This was observed metallographically in cast alloys, but not determined experimentally by DTA, which was almost certainly because the experiment was insufficiently sensitive to differentiate both the Laves and $\eta$ formation.

A known weakness of the SG approach is for steels, where fast $\mathrm{C}$ and $\mathrm{N}$ diffusion causes the model to break down. However, it is noted that the SG model can be modified to take into account the effect of fast $\mathrm{C}$ and $\mathrm{N}$ diffusion so that steels can be considered [15]. Such a model (SGM) has been implemented in the software package JMatPro $[19,20]$ by considering that $\mathrm{C}$ and $\mathrm{N}$ will diffuse sufficiently rapidly such that their composition in the growing austenite or ferrite phases will be equal to that of the solid at the growing solid/liquid interface. Within the current model, it is not yet possible to consider the solid state reaction between ferrite and austenite whereby the ferrite is consumed by the growing austenite in a peritectic reaction. However, the kinetics of this transformation may be slow enough such that it is reasonable to assume that the peritectic reaction 
is not completed during solidification. Having said this, it is clear that in many steels the SGM model provides results that are actually quite close to equilibrium where the full peritectic transformation is complete (Fig.3) and it may be that an equilibrium calculation is the most accurate model to use, as suggested by Saunders [6].

\subsection{Modelling of physical properties}

A major achievement of the JMatPro software project has been the development of an extensive database for the calculation of physical properties that can be linked to its thermodynamic calculation capability. For individual phases in multi-component systems, properties, such as molar volume, thermal conductivity, Young's modulus, Poisson's ratio etc., are calculated using simple pair-wise mixture models, similar to those used to model thermodynamic excess functions in multi-component alloys [14]. It is possible to include ternary or higher order effects where appropriate. Once the property of the individual phase is defined, the property of the final alloy can be calculated using mixture models that can account for the effect of microstructure on the final property $[23,24]$. Such models, which were developed for 2-phase systems, have been extended to allow calculations to be made for multi-phase structures [25].

Extensive databases of relevant parameters now exist for most of the major phases in $\mathrm{Al}-, \mathrm{Fe}-\mathrm{Mg}$-, $\mathrm{Ni}$ - and Ti-alloys, which have been tested both in the liquid and solid state against experimental measurement $[15,16,17,18,19,20]$. Utilising well established relationships between certain properties, (e.g. thermal and electrical conductivity), minimises the number of property databases that need to be created and allows the following properties to be modelled - volume, density, expansion coefficient, Young's, bulk and shear moduli, Poisson's ratio, thermal conductivity and diffusivity, electrical conductivity and resistivity, liquid viscosity and diffusivity.

\section{EXAMPLE CALCULATIONS}

The ability to calculate thermo-physical and physical properties at will for many type of alloy type is important for a number of reasons. Firstly, information can be readily gained for alloys where measurements are not available. Because there is a distinct lack of reliable measurements for solidification properties of many alloys, this is, in itself, a highly valuable capability. It is also possible to calculate quickly and self-consistently, how such properties may change as the alloy composition varies within the alloy specification. Further a great deal of detailed information comes with the current calculation route that is otherwise either impossible, or extremely difficult, to experimentally determine. For example properties of the liquid in the mushy zone, which is the controlling factor in many types of defect, e.g. freckles, macrosegregation, shrinkage porosity, etc..

\subsection{Variations in behaviour within an alloy composition specification range}

Because for the lack of data concerning thermo-physical and physical properties for multicomponent alloys, properties are often defined for a typical alloy. For example, as for the case of the $718 \mathrm{Ni}$-based superalloy mentioned in section 1. However, it is not always clear that a typical alloy can be defined. Certain alloys are rather sensitive to small composition variations, while others, for example solid solution alloys, may not be so sensitive. It may also be that the composition specification for that alloy is wide, which is the case for many well-known and wellused alloys. Some excellent examples of the varying behaviour of Al-alloys, of the same designation, are shown by Bakerud et al [22].

We will look here at the Al-alloy ADC12 (Japanese designation). This is a high Si and Cu alloy with quite high allowable levels of other elements such as Fe and $\mathrm{Ni}$. Two compositions have been 
tested, one at the low level of specification for each element, the other the high level. While such a choice might be expected to show the largest difference in behaviour, it is not necessarily the case. Depending on partition behaviour and effect on invariant reactions, it is possible for an increase in one element to cancel out the effect of another. Having noted this, the difference in behaviour of the two ADC12 alloys is striking enough.

Figure 4 shows fractions solid vs. temperature plots for the two alloys. The high specification (HS) alloy is hypereutectic, with primary $\mathrm{Si}$ and intermetallics forming over a significant temperature range, while the low specification alloy (LS) forms about $22 \%$ of primary Al. At the start temperature of eutectic solidification for the HS alloy $\left(565^{\circ} \mathrm{C}\right)$ the fraction solid for the LS alloy is $\sim 65 \%$, in comparison to $\sim 5 \%$ for the HS alloy. The discrepancies between fraction solid at any temperature remain high for much of solidification, though both finally solidify via a eutectic involving $\mathrm{Al}_{2} \mathrm{Cu}$. Due to the very different behaviour of the two alloys, there will be a subsequent effect on all of the properties as a function temperature. An example is the volume change (in the range $450-650^{\circ} \mathrm{C}$ ), which again for most of the temperature range is quite different for the two alloys (Figure 5).

In the fine detail there can be substantial differences between alloys, with much smaller composition variations producing quite substantial differences in behaviour of the physical property of the liquid. In this case we have taken the Al-alloy 356. In Figure 6 the density of an alloy with the composition $\mathrm{Al}-0.01 \mathrm{Cu}-0.2 \mathrm{Fe}-0.3 \mathrm{Mg}-0.02 \mathrm{Mn}-7 \mathrm{Si}-0.025 \mathrm{Zn}(\mathrm{wt} \%)$ is shown. In this circumstance, there is a slight density inversion as $\mathrm{Mg}$ segregates into the liquid below the Silicon eutectic. However, when $\mathrm{Cu}, \mathrm{Mn}$ and $\mathrm{Zn}$ levels increase to higher levels $(0.25 \% \mathrm{Cu}, 0.3 \mathrm{Mn}$, $0.35 \mathrm{Zn}$ ) the behaviour of the liquid in the mushy zone dramatically changes (Figure 7 ). During the initial Al solidification the behaviour is little different than before however, the behaviour during the eutectic part of solidification is quite different with the liquid phase now becoming much more dense.

\subsection{Behaviour of the liquid in the mushy zone}

Probably the two most important factors in liquid behaviour in the mushy zone are the density and viscosity. It is possible to measure these in the fully liquid state but extrapolation of such properties into the mushy zone is dangerous, primarily because the liquid composition changes quite markedly in the mushy zone with subsequent knock-on effects for liquid properties.

The behaviour of the 356 alloys shown in the previous section 3.1 demonstrated how significant variation occurs in the liquid density between alloys of only slightly different composition. However it can also be seen most clearly that the behaviour of the liquid in the mushy zone is markedly different to that extrapolated from the stable liquid. A series of examples will now be shown emphasising this fact.

In Ni-based single crystal superalloys, freckle formation is a significant problem and is caused by a density inversion in the liquid. This caused by segregation of heavy elements such as $\mathrm{W}$ and Re into the solid and light elements such as $\mathrm{Ti}$ and $\mathrm{Al}$ into the liquid. Some segregation of Ta occurs to the liquid, but is insufficient to counterbalance the effect of the other segregation. Figure 8 shows the calculated density of the liquid in the mushy zone for the alloy SRR 99 [18].

The case of SRR 99 is quite a severe case, but not uncommon in such alloys. However, there is a general problem if extrapolations of high temperature properties are used for other alloys, particularly if they have a long freezing range. Figure 9 shows the liquid density of a ZMC 711 
Mg-alloy containing $\mathrm{Cu}$ and $\mathrm{Zn}$. In this case both $\mathrm{Cu}$ and $\mathrm{Zn}$ segregate strongly into the liquid causing a rapid rise in density. At the end of solidification the density of the liquid approaches twice that of the original high temperature liquid. The total density of the alloy is counterbalanced by the formation of $\mathrm{Mg}$ solid which itself has a lower density than the liquid because almost all of the $\mathrm{Cu}$ and $\mathrm{Zn}$ segregate to the liquid. As well, the viscosity is strongly affected (Figure 10). In this case there is both the elemental segregation to the liquid increasing the viscosity as well as a natural increase with decreasing temperature causing the viscosity of the final liquid to be almost 5 times that of the high temperature liquid. In steels, freezing ranges can be quite narrow. However, $\mathrm{C}$ segregation into the liquid always occurs. Figure 11 shows the liquid density in a low alloy steel, showing the inversion caused by $\mathrm{C}$ segregation.

\section{DISCUSSION}

A series of calculations for the physical properties of $\mathrm{Al}, \mathrm{Fe}, \mathrm{Mg}$ and Ni-based alloys have been made and results displayed. The calculations accentuate the fact that the properties of an alloy can substantially change within a composition specification and extrapolation of high temperature liquid properties into the mushy zone will invariably be inaccurate.

To be able, at will, to calculate all critical physical properties during solidification with good reliability is a significant advance. It removes uncertainty both if new alloys are being used and where information concerning existing alloys is incomplete. Further, the calculations invariably provide greater detail than experiment.

While it is recognised that for low-level applications detailed physical properties may not alter casting simulations to a significant degree, for example in shell-freezing type simulations, the physical properties become increasingly important when greater detail is required or when problems to be solved become more complex. For example, for use in various defect models or if accurate cooling rates as a function of temperature are required or if liquid transport through interdendritic regions is being modelled, etc..

\section{SUMMARY AND CONCLUSIONS}

It is now possible to calculate thermo-physical and physical properties during solidification and previous validation work has shown that good results are obtained in comparison to experiment. This means that properties can now be calculated for many alloys where no experimental information exists. It further means that incomplete experimental information can be augmented and internally self-consistent input can be used as input for inverse models to estimate difficult properties such as heat transfer coefficient at the ingot/mold interface.

In the present paper it is further shown that

(1) substantial differences in properties may occur within a specification range of an alloy designation, and

(2) experimentally determined high temperature liquid properties cannot be extrapolated into the mushy zone with any confidence.

(3) Both of these problems can be overcome by using the present calculation method. 


\section{REFERENCES}

1. P. N. Quested, K. C. Mills, R. F. Brooks. A. P. Day, R. Taylor and H. Szelagowski, Proc. Conf. Liquid Metal Processing 1997, Santa Fe, NM, U.S.A., Sept.16-19, American Vacuum Society, 1997, 1.

2. W. D. Cao, R. L. Kennedy and M. P. Willis, Superalloys 718, 625 and Various Derivatives, (Ed.: E. A. Loria), TMS, Warrendale, PA, 1991, 147.

3. W. Zhang, P. D. Lee and M. McLean, Met. Mater. Trans. A, 2002, 33A, 1.

4. R. M. Ward, M. D. Barratt, M. H. Jacobs and A. L. Dowson, Proc. Conf. Liquid Metal Processing 2003, Nancy, France, Sept.21-24, 2003, 223.

5. Data downloaded from web address http://metalcasting.auburn.edu/data/data.html.

6. N. Saunders, Solidification Processing 1997, (Eds.: J. Beech and H. Jones), Univ. Sheffield, Sheffield, 1997, 362.

7. N. Saunders, Materials Science Forum, 1996, 217-222, 667.

8. $\quad$ N. Saunders, Light Metals 1997, (Ed.: R. Huglen), TMS, Warrendale, PA, 1997, 911.

9. R. A. Harding and N. Saunders, Trans. American Foundryman's Society, 1997, 105, 451.

10. W. J. Boettinger, U. R. Kattner, S. R. Coriell, Y. A. Chang and B. A Mueller, Modelling of Casting, Welding and Advanced Solidification Processes, VII, (Eds.: M. Cross et al.), TMS, Warrendale, PA, 1995, 649.

11. B. A. Boutwell, R. G. Thompson, N. Saunders, S. K. Mannan, and J. J. deBarbadillo, Superalloys 718, 625, 706 and Various Derivatives, (Ed.: E. A. Loria), TMS, Warrendale, PA, 1996, 99.

12. U. Grafe, D. Ma, A. Engstrom and S. G. Fries, Modelling of Casting, Welding and Advanced Solidification Processes VIII, (Eds.: B. G. Thomas and C. Beckermann), TMS, Warrendale, PA, 1998, 227.

13. M. S. A. Karunarate, D. C. Cox, P. Carter and R. C. Reed, Superalloys 2000, (Eds.: K. A. Green, T. M. Pollock and R. D. Kissinger), TMS, Warrendale, PA, 2000, 263.

14. N. Saunders and A. P. Miodownik, CALPHAD - Calculation of Phase Diagrams, Pergamon Materials Series vol.1, (Ed.: R. W. Cahn), Elsevier Science, Oxford, 1998.

15. N. Saunders, X. Li. A. P. Miodownik and J.-Ph. Schillé, Modelling of Casting, Welding and Advanced Solidification Processes X, (Eds.: D. Stefanescu, J. A. Warren, M. R. Jolly and M. J. M. Krane), TMS, Warrendale, PA, 2003, 669.

16. N. Saunders, X. Li. A. P. Miodownik and J.-Ph. Schillé, Light Metals 2003, (Ed.: P. Crepeau), Warrendale, PA: TMS, 2003, 999.

17. N. Saunders, X. Li. A. P. Miodownik and J.-Ph. Schille, Magnesium Technology 2003, (Ed.: H. I. Kaplan), Warrendale, PA: TMS, 2003, 135.

18. N. Saunders, X. Li. A. P. Miodownik and J.-Ph. Schillé, Proc. Conf. Liquid Metal Processing 2003, Nancy, France, Sept.21-24, 2003, 253.

19. N. Saunders, Z. Guo, X. Li, A. P. Miodownik and J-Ph. Schillé, JOM, December, 2003, 60.

20. N. Saunders, X. Li, A. P. Miodownik and J.-Ph. Schillé., Materials Design Approaches and Experiences, (Eds.: J.-C. Shao, M. Fahrmann and T. M. Pollock), TMS, Warrendale, PA, 2001, 185.

21. T. W. Clyne and W. Kurz, Metall. Trans. A, 1981, 12A, 965

22. L. Backerud, E. Krol and J. Tamminen, Solidification Characteristics of Aluminium Alloys: Vols.1 and 2, Tangen Trykk A/S, Oslo, 1986

23. Z. Fan, P. Tsakiropoulos and A. P. Miodownik, J. Mat. Sci.,, 1994, 29, 141.

24. Z. Fan, Phil.Mag.A, 1996, 73, 663.

25. A. P. Miodownik, N. Saunders and J.-P. Schillé, unpublished research. 
Table I. Comparison between experimentally determined DTA results [11] and a Scheil-Gulliver simulation for a 706 alloy (temperatures all in ${ }^{\circ} \mathrm{C}$ )

\begin{tabular}{cccccc}
\hline & Liquidus & $\begin{array}{c}\text { MC } \\
\text { start }\end{array}$ & $\begin{array}{c}\text { Laves } \\
\text { start }\end{array}$ & $\begin{array}{c}\eta \\
\text { start }\end{array}$ & $\begin{array}{c}\text { Solidifi- } \\
\text { cation end }\end{array}$ \\
\hline Centre (DTA) & 1381 & 1240 & 1164 & & \\
Edge (DTA) & 1388 & 1261 & & & \\
Calculated & 1388 & 1256 & 1168 & 1144 & 1128 \\
\hline
\end{tabular}



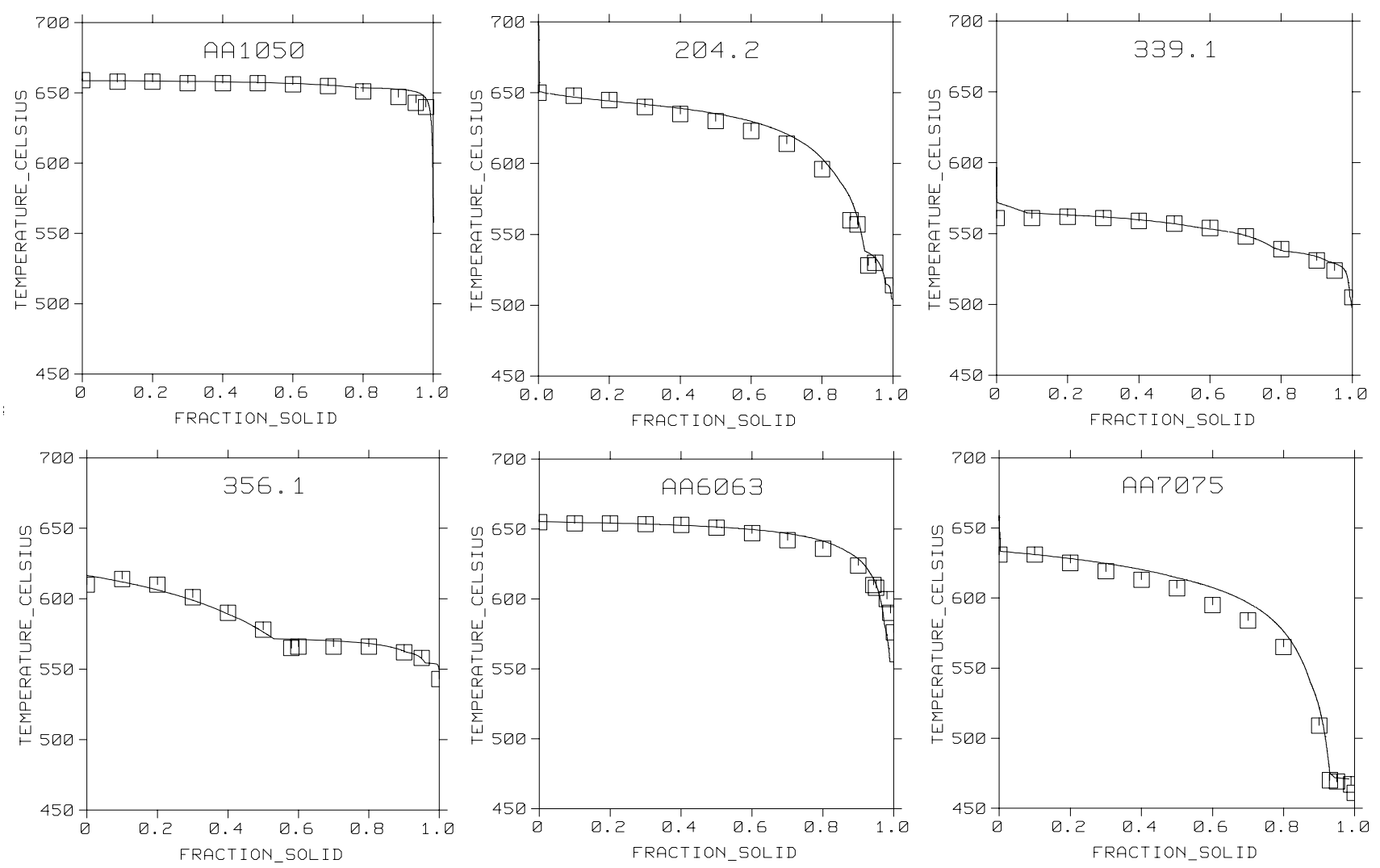

Figure 1. Fraction solid vs. temperature plots for various Al-alloys calculated under 'Scheil' conditions with experimental results ( $\square$ ) of Backerud et al [22] shown for comparison. 


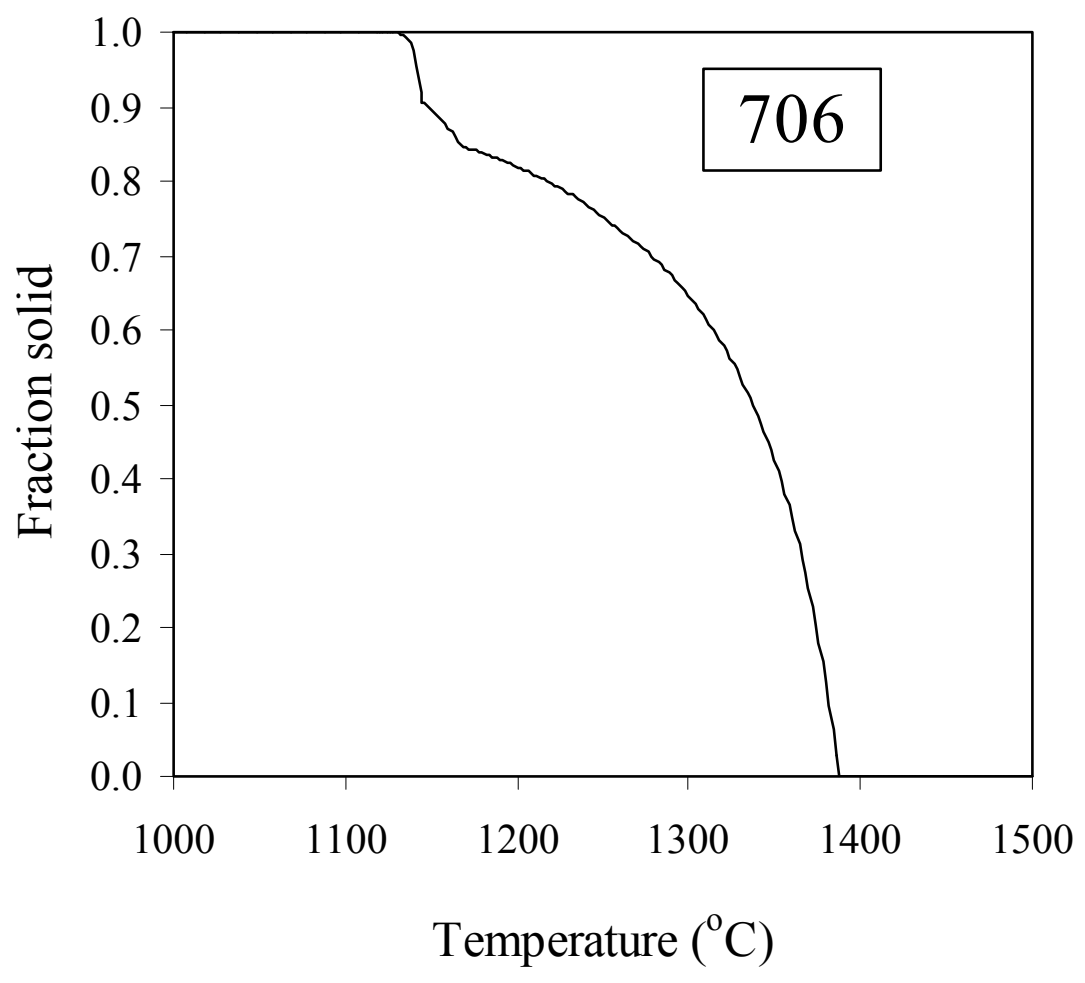

Figure 2. Calculated fraction solid vs. temperature plot for solidification of alloy 706.

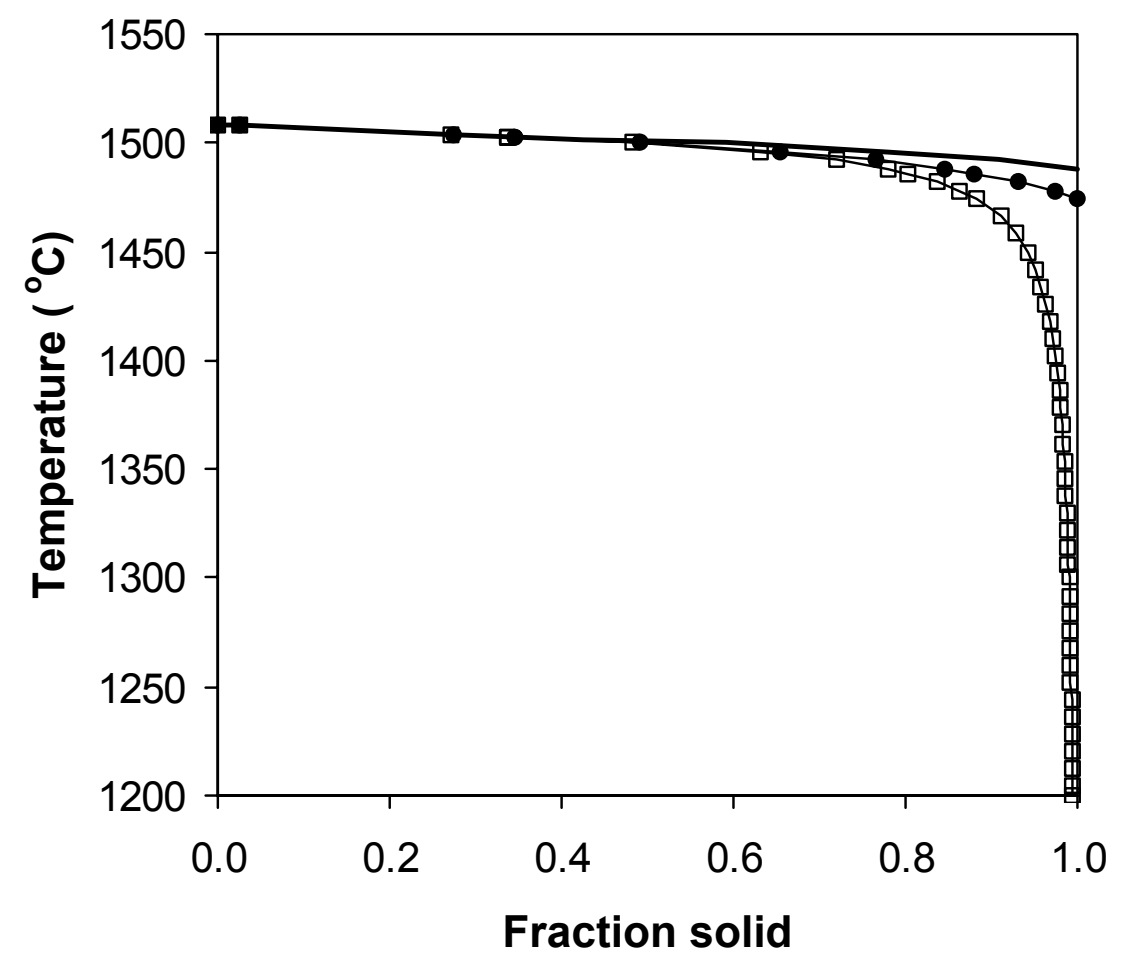

Figure 3. Fraction solid vs. temperature curves for solidification of a 3310 steel calculated under (一) equilibrium, ( $\square$ ) SG and $(\bullet)$ SGM conditions [15]. 


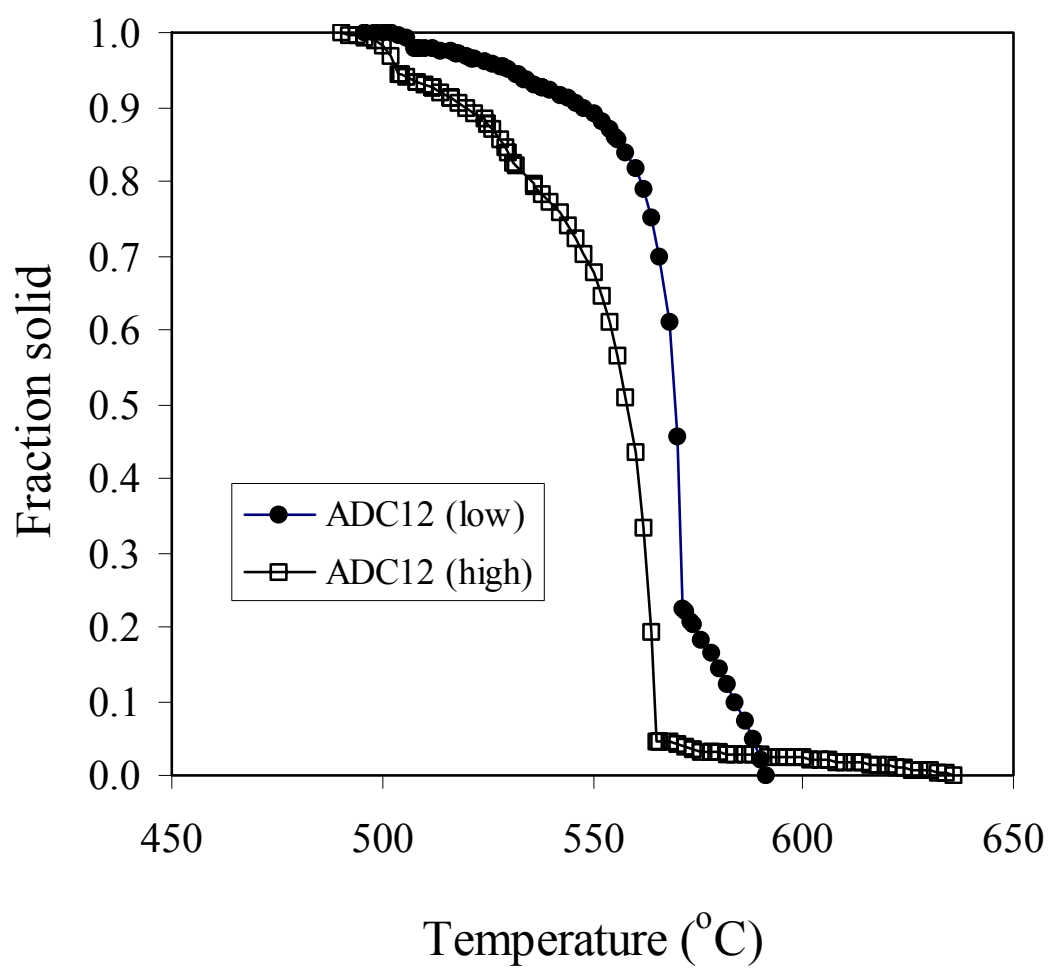

Figure 4. Calculated fraction solid vs.temperature plots of two ADC12 Al-alloys.

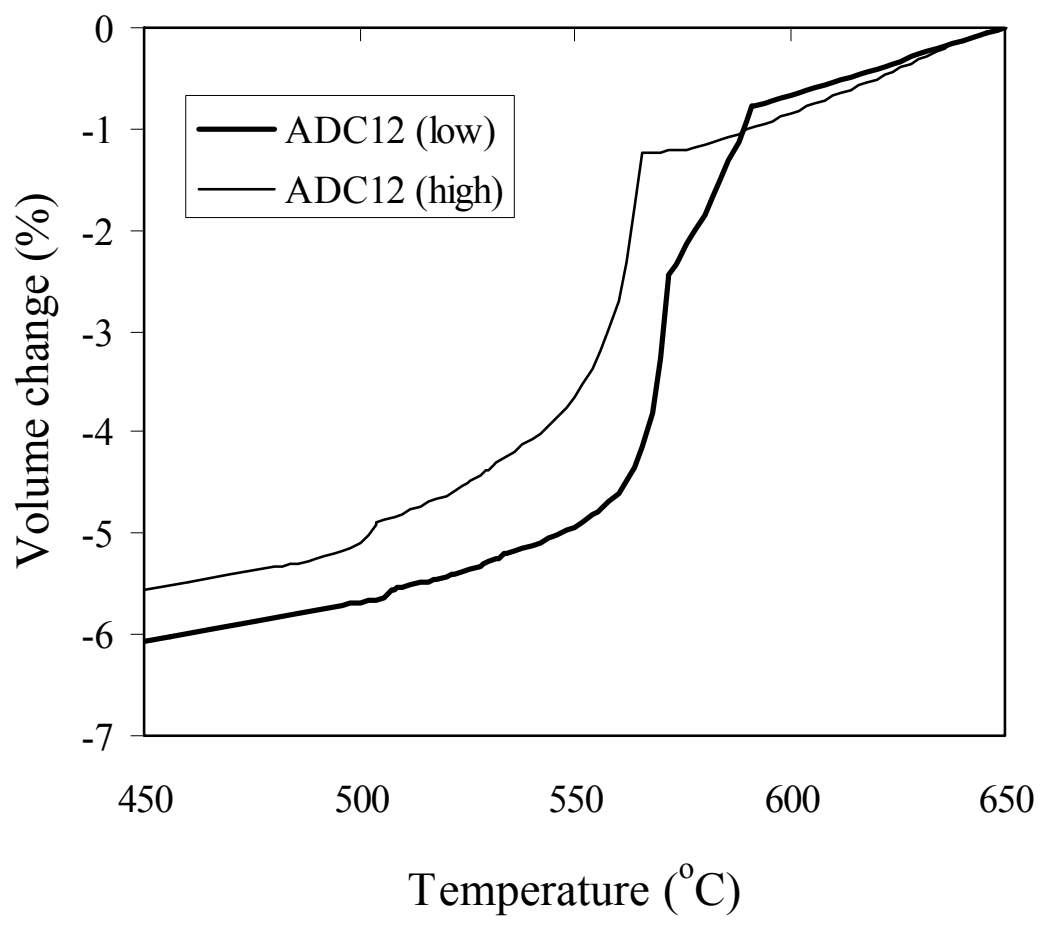

Figure 5. Calculated volume change vs. temperature plots of two ADC12 Al-alloys. 


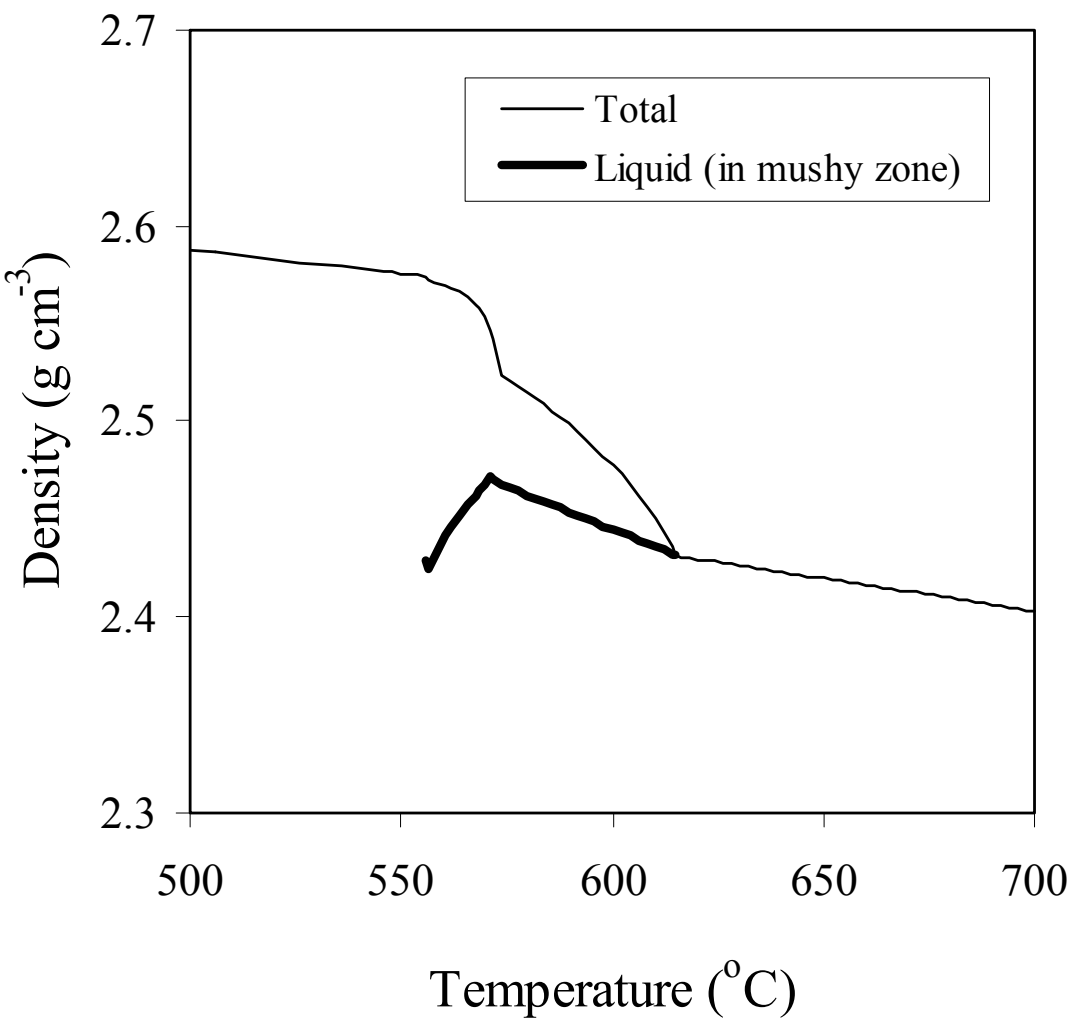

Figure 6. Calculated density of a 356 Al-alloy (with low $\mathrm{Cu}, \mathrm{Mn}$ and $\mathrm{Zn}$ ) during solidification. Bold line shows density of the liquid in the mushy zone

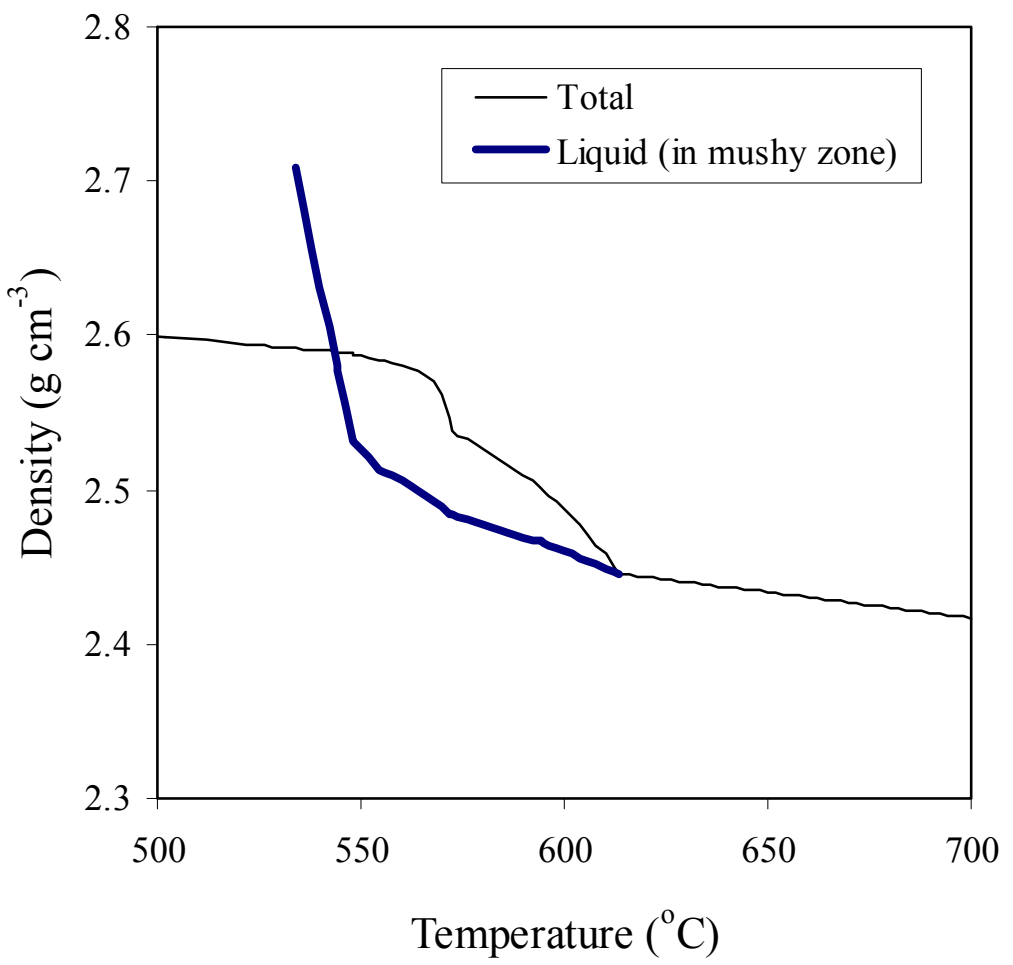

Figure 7. Calculated density of a 356 Al-alloy (with high $\mathrm{Cu}, \mathrm{Mn}$ and $\mathrm{Zn}$ ) during solidification. Bold line shows density of the liquid in the mushy zone 


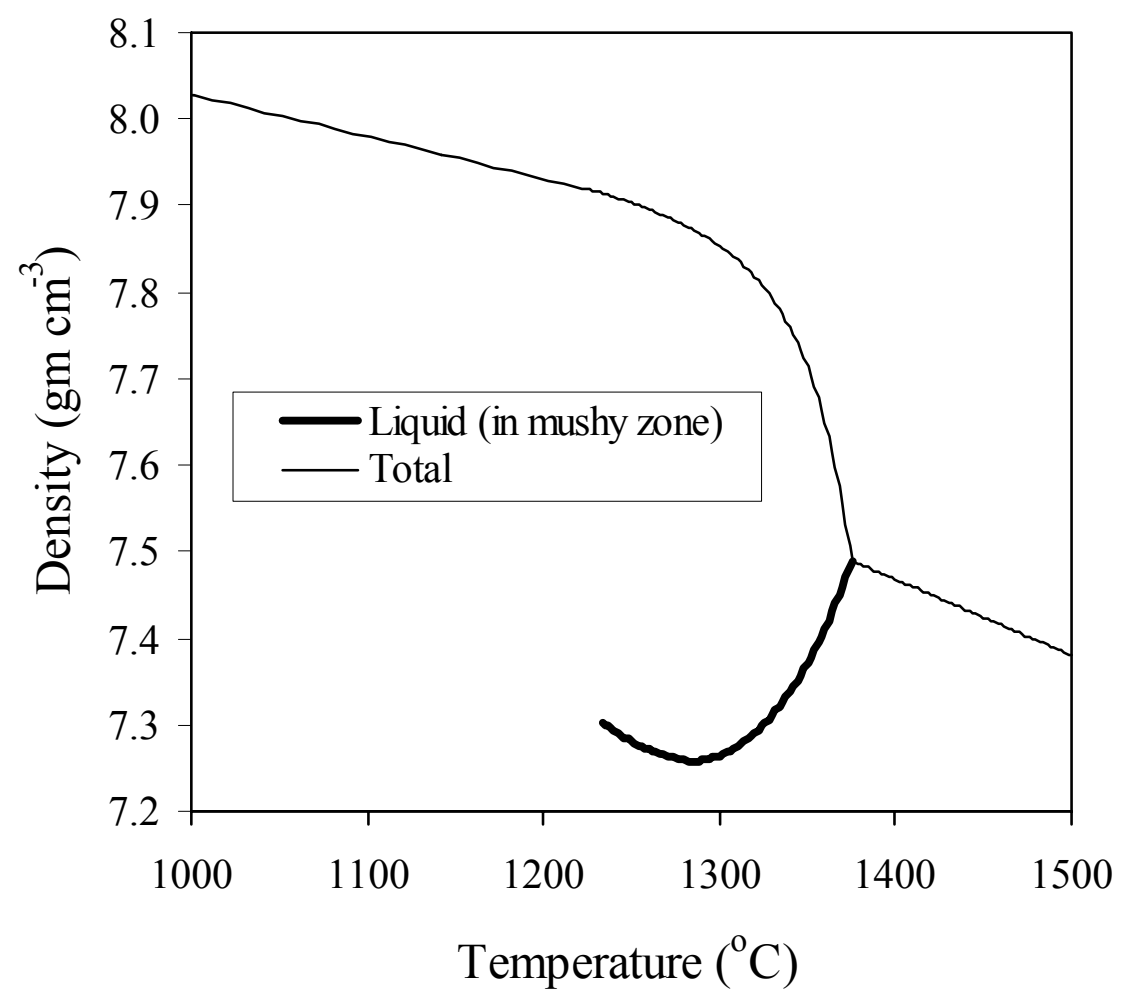

Figure 8. Calculated density of a SRR99 single crystal superalloy during solidification [18]. Bold line shows density of the liquid in the mushy zone

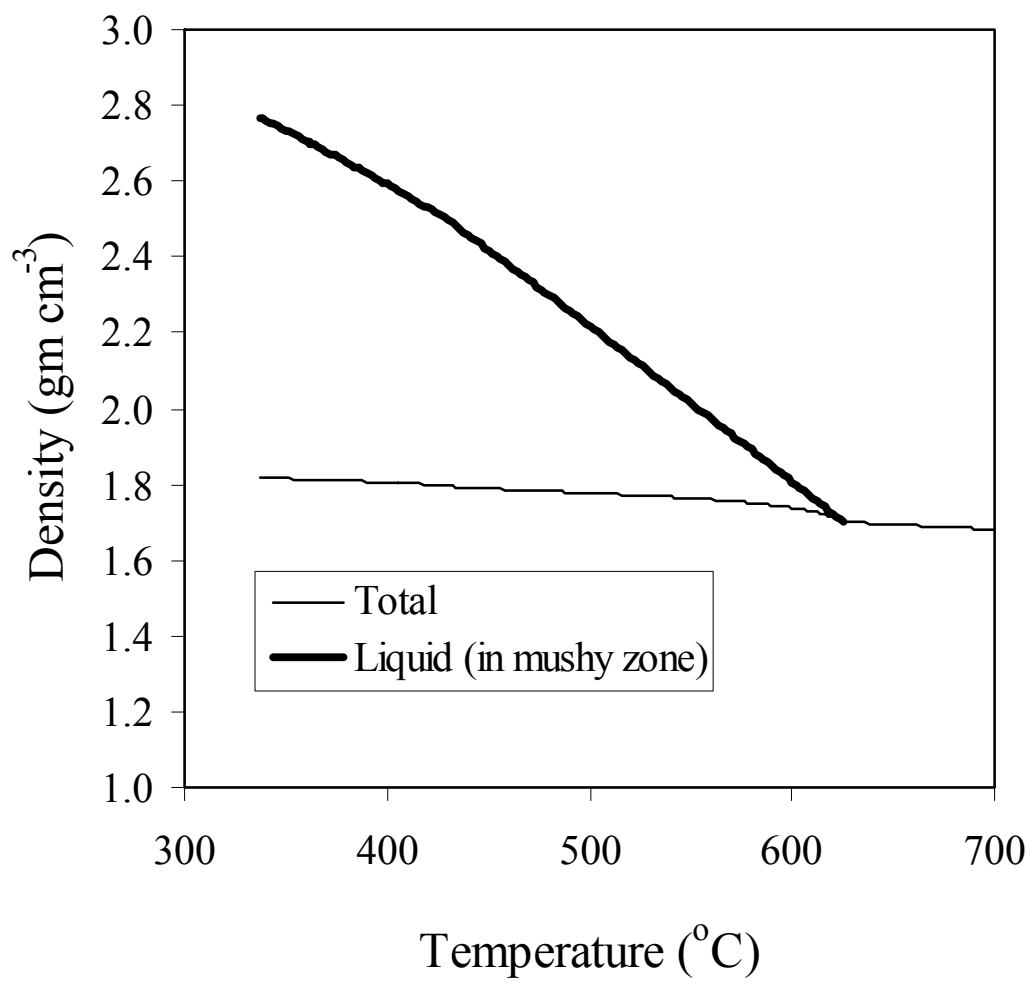

Figure 9. Calculated density of a ZMC711 Mg-alloy during solidification. Bold line shows density of the liquid in the mushy zone 


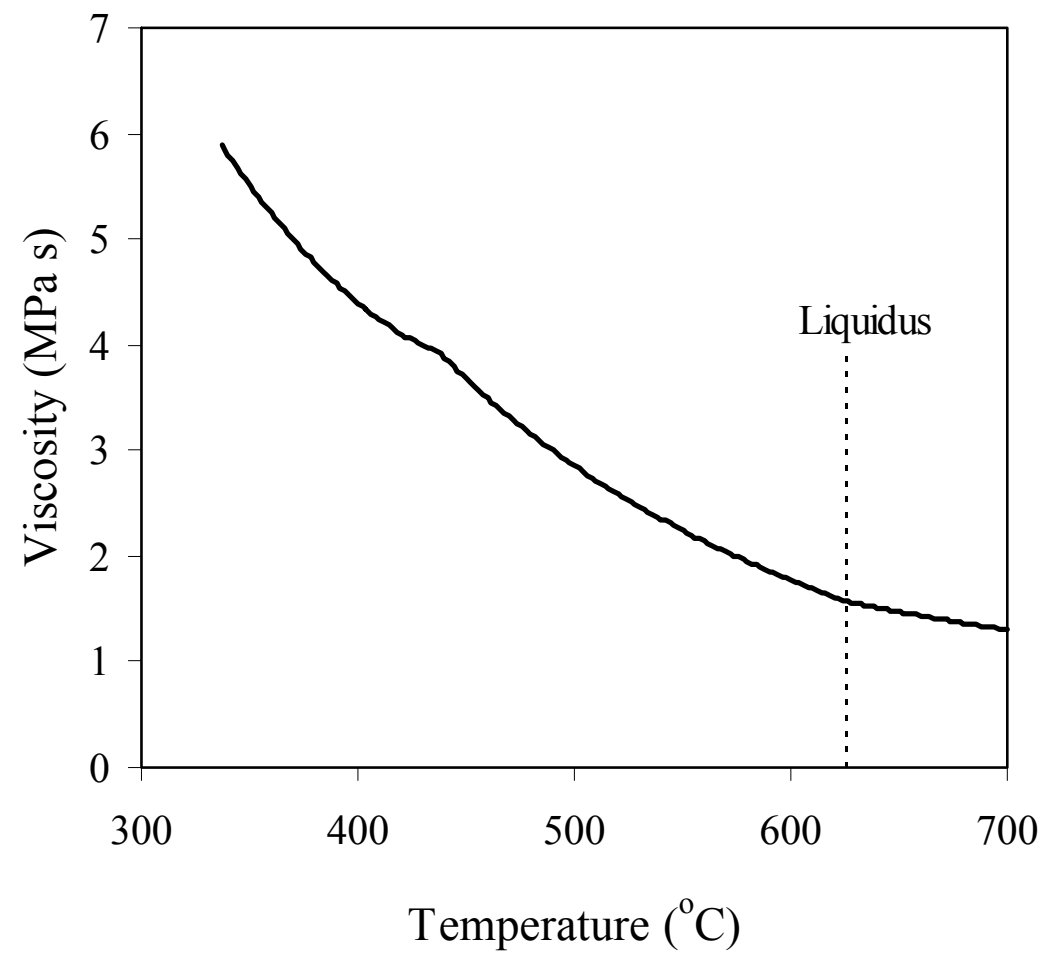

Figure 10. Calculated viscosity of a ZMC711 Mg-alloy during solidification.

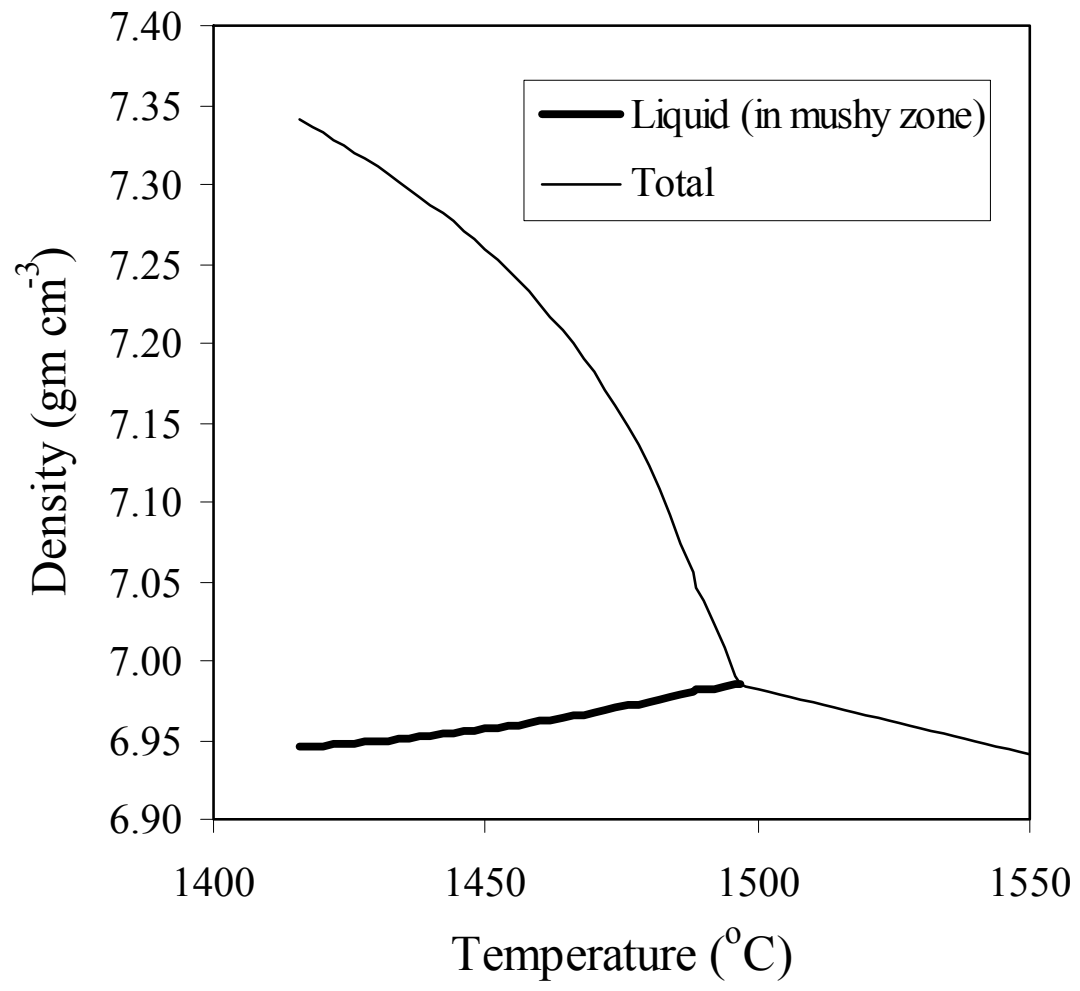

Figure 11. Calculated density of a low alloy steel during solidification. Bold line shows density of the liquid in the mushy zone 